\title{
Nudos críticos en la comprensión ontológica de la educación inclusiva
}

\section{Critical knots in ontological understanding of inclusive education}

ALDO OCAMPO-GONZÁLEZ

\section{Resumo}

A educação inclusiva não define claramente uma nova condição de humanidade, analisa preocupações de ordem contingente vinculadas a processos ideológicos, discursivos e relações de poder que participam da configuração do poder da condição de ser humano, fabricando novos códigos de legibilidade. O objetivo deste trabalho é analisar a matriz de produção ontológica da educação inclusiva e suas repercussões materiais e subjetivas na vida escolar. $O$ método utilizado utiliza a pesquisa documental crítica. Entre suas principais conclusões estão: a) a construção de uma pragmática epistemológica micropolítica e b) a criação de uma concepção ontológica neo-materialista que privilegia a multiplicidade de modos de existência do ser humano.

Palavras-chave: Inclusão. Ontologia do menor. Matriz essencialista-individualista. Ontologia neo-materialista. Singularidades múltiplas.

\begin{abstract}
The question about the definitional forms of the social, political and educational subject in the framework of inclusive education constitutes their activity based on the essentialist-individualist matrix to justify the task from the imposition of the epistemic and didactic legacy of special education. The method used is the critical document review. The work concludes by stating that the ontological policy of inclusive education is based on the approaches of the molecular revolution, configures a diagram of contingent, relational and transitive positions that reveal the ontological nature of the multitude of forms of the buman being.
\end{abstract}

\footnotetext{
${ }^{1}$ Chileno. Teórico y ensayista educativo. Director fundador del Centro de Estudios Latinoamericanos de Educación Inclusiva (CELEI), Chile. Doctor en Ciencias de la Educación, aprobado Sobresaliente mención 'Cum Laude' por unanimidad por la Universidad de Granada, España. Actualmente, cursa el Postdoctorado en Educação, Contextos Contemporâneos e Demandas Populares en la UFRRJ, Brasil. Es creador de la epistemología de la educación inclusiva.
} 
Keywords: Inclusion. Ontology of the lesser. Essentialist-individualist matrix. Neo-materialist ontology. Multiple singularities.

\section{Resumen}

La educación inclusiva no define una nueva condición de humanidad con claridad, analiza preocupaciones de orden contingentes ligadas a procesos ideológicos, discursivos y relaciones de poder que participan en la configuración de la potencia del estatus de ser humano, fabricando nuevos códigos de legibilidad. El objetivo de este trabajo consiste en analizar la matriz de producción ontológica de la educación inclusiva y sus repercusiones materiales y subjetivas en la vida escolar. El método empleado recurre a la investigación documental crítica. Entre sus principales conclusiones destacan: a) la construcción de una pragmática epistemológica de orden micropolítica y b) la creación de una concepción ontológica de carácter neo-materialista que favorezca la multitud de modos de existencia del ser humano.

Palabras clave: Inclusión. Ontología de lo menor. Matriz esencialista-individualista. Ontología neo-materialista. Singularidades múltiples.

\section{Introducción: incluir y comprender el presente, dos mandatos cruciales}

La definición del sujeto social, político y educativo en el marco de la ‘inclusión’ y la 'educación inclusiva', constituye un punto espinoso; especialmente, por su raigambre de sujeción a la matriz esencialista-individualista sobre la que se erigen sus planteamientos onto-céntricos y onto-normativos empleados para justificar su tarea a partir de la imposición del legado epistémico y didáctico de la educación especial -principal fracaso cognitivo en la aproximación y comprensión del objeto de la educación inclusiva-.

Tal fracaso cognitivo deviene en una singular estrategia de edipización heurística sostenida y reproducida por las agendas de investigación mainstream a través de la metáfora de lo neo-especial, agudizando un compromiso con las bases del humanismo clásico y el sustancialismo, que sea dicho de paso, participan de la regulación de la matriz de esencialismos-individualismos. Si asumimos desde una concepción más amplia los propósitos ontológicos del campo, retorna la tarea de subvertir los códigos de legibilidad de los sujetos educativos y sociales a través del compromiso con el anti-humanismo que, según Braidotti (2018), si bien, no define una nueva condición de humanidad con claridad, traslada la mirada hacia 
Nudos críticos en la comprensión ontológica de la educación inclusiva

preocupaciones de orden contingentes ligadas a procesos ideológicos, discursivos y relaciones de poder que participan en la configuración del estatus de ser humano.

Un compromiso ontológico de carácter anti-humanista actúa creando una cartografía sobre un presente suspendido y desconocido, incide en la construcción colectiva de sujetos-ciudadanos a través de otros criterios de legibilidad en la intimidad de la experiencia escolar. La inclusión construye nuevas formas de subjetividad y modos de relacionamientos desconocidos. Una de las demandas ontológicas que asume la educación inclusiva consiste en construir modos-otros de concebir experiencias y practicar la humanidad.

En respuesta a esta tarea crítica emerge la construcción de una pragmática epistemológica de orden micropolítica dedicada a crear elementos de liberación de amplias colectividades de sujetos inscritos en la zona del no-ser o del no-existente. Tarea que pretende la desestabilización de los principios, marcos de valores y concepciones que justifican la función de la inclusión en el marco de las demandas de la zona del ser o espacialidad de la hegemonía, caracterizada por la creación de un corpus de códigos de ordenación que trabajan para reconocer los problemas de los Otros sin crear coordenadas de alteridad reales que permitan liberar la vida de las personas de experiencias que agudizan la exclusión y la opresión, por ejemplo.

La educación inclusiva enfrenta el reto de asumir una concepción ontológica y ética coherente con los principios del neo-materialismo o del materialismo nómada, ratificando una acción crítico-afirmativa con el presente, traducida como

[...] todas las entidades humanas y no humanas son sujetos nómadas en proceso, en perpetuo movimiento, inmanentes a la vitalidad de la materia auto-ordenada. Acercarse al presente produce pues un efecto multifacético: por un lado, la aguda conciencia de lo que somos dejando de ser (el fin de lo actual) y por otro la percepción -en diferentes grados de claridad- de lo que estamos en el proceso de convertirnos (la actualización de lo virtual). Ambos fenómenos ocurren a la vez, de forma no lineal, tiempo-continuo (BRAIDOTTI, 2018, p.6-7). 
Si la educación inclusiva forja un saber del presente, no busca detenerse en la crítica de este, inscribe su fuerza de producción en la actualización creativa de lo virtual, insistiendo en el beneficio ético-político del materialismo cognoscitivo que según Braidotti (2018), trabaja a favor de

[...] la interacción entre el presente como actual y el presente como virtual deletrea los ritmos de formación del sujeto. Por extensión, lo posthumano como figuración cartográfica es una rama de pensamiento crítico contemporáneo que nos permite pensar en lo que "somos" dejando de ser, por ejemplo, la categoría eurocéntrica del "Hombre" universal. También sostiene, sin embargo, el esfuerzo por dar cuenta de lo que "somos" en el proceso de devenir (p.7).

Si la política ontológica de la educación inclusiva se funda en los planteamientos de la revolución molecular, entonces, configura un diagrama de posiciones contingentes, relacionales y transitivas que trabajan a favor de la multitud de modos de existencia del ser humano. Nos invita a explorar y habitar formas aún no realizadas del ser; premisa que entraña una sólida empresa creativa. Esta figura ontológica demanda la creación de conceptos para leer un presente caótico e impredecible. En efecto,

[...] la creatividad, la imaginación, se reconecta constantemente con la totalidad virtual de un bloque de experiencias pasadas y afectos, que se recomponen como acción en el presente, dándose cuenta de su potencial insatisfecho. Este modo de crítica afirmativa es un ejercicio de sincronización temporal y contingente, que sostiene, en el presente, la actividad de actualizar lo virtual (BRAIDOTTI, 2018, p.8).

Si el ser humano se encuentra en proceso de mutación es necesario consolidar una nueva imagen de pensamiento que obligue a reconocer que toda praxis cultural se encuentra incorporada, incrustada por múltiples devenires y fuerzas de singularización. La educación inclusiva no cumple su función ante los retos del mundo contemporáneo, en parte, porque carece de conceptos adecuados para leer el presente. Uno de sus propósitos onto-políticos consiste en aprender a comprender las formas de irrupción de la multiplicidad y sus configuraciones en la vida actual. 


\section{Un territorio con múltiples convergencias heurísticas}

La educación inclusiva construye un emergente campo de investigación centrado en una diversidad de problemas, no en espacios disciplinares canónicos. Su actividad cognitiva reafirma una acción post-disciplinar atravesada por diversas descendencias y trayectorias analítico-metodológicas y convergencias heurísticas que oscilan entre lo multi-, lo inter-, lo trans-, lo extra- e incluso, lo anti-disciplinar.

Es un territorio que se nutre de aportes que provienen de campos alejados, ajenos, muchas veces híbridos, emergentes y marginales a los diálogos e interacciones heurísticas legitimadas en la intimidad de las Ciencias de la Educación. Persigue responder a los Otros múltiples excedentes del humanismo clásico a través de la contribución de diversos proyectos políticos, éticos y de conocimiento en resistencia, que comparten la tarea de interrogar las formas de mono-educacionismo acerca de la injusticia y la diversidad de sistemas de opresión y producción de desigualdades a nivel psíquico y material.

La educación inclusiva es un territorio heurístico inacabado atravesado de prácticas de producción del conocimiento en devenir, cuyos problemas se encuentran arraigados en el presente. Las cadenas de herencias que definen sus modalidades de vinculación con lo especial constituyen uno de sus principales errores cognitivos. Su construcción epistemológica organiza su actividad a partir de un dispositivo multi-éxodo que escapa a las formas definitorias de múltiples proyectos de conocimiento que participan en su ensamblaje. Construye una práctica crítica que corre el marco a través de una operación dialéctica anti-hegeliana donde se inscriben las fuerzas de desvinculación y rearticulación.

La naturaleza del conocimiento de la educación inclusiva de carácter postdisciplinar no solo abre nuevos ángulos de visión e interviene en problemas de naturaleza contingente, afecta a diversos territorios y prácticas interpretativas y discursivas, explícita una "nueva energía metadiscursiva por parte de las disciplinas" 
(BRAIDOTTI, 2018, p.13). Su naturaleza post-disciplinar no solo reafirma que su red objetual no pude ser delimitada en los paradigmas de ninguna disciplina en particular, sino más bien, legitima una morfología que da vida a una red agenciamientos heurísticos que proceden de formas y aparatos de descendencia híbridas y ensamblajes heterogéneos, consolidando relaciones epistémicas sin precedentes.

La educación inclusiva presenta, además, una naturaleza porosa y un centro epistémico relacional, territorio complejo, dinámico, que parece nunca detenerse. La educación inclusiva es un compromiso con las demandas del devenir minoritario, un dispositivo de aceleración de lo menor. Es esto, lo que impulsa los modos alterativos de comprender al ser y a sus tramas de devenir.

\section{Las bases ontológicas de la educación inclusiva se fundamentan en una concepción neo- materialista}

El concepto de 'necesidades educativas especiales' tanto en su versión estática como interactiva devela una convención normativa regulada por criterios ambiguos y homogéneos, devenidos en usos inflacionarios y en mecanismos instrumentales de regulación de las prácticas de enseñanza. Su funcionamiento opera en proximidad a modos específicos de entender las dificultades que experimentan determinados estudiantes desde una perspectiva homogénea devenida en un sistema normativo generalizado.

El sintagma 'necesidades educativas especiales' suprime las diferencias que existen entre la diversidad de estudiantes atravesados en su experiencia subjetiva por diversas clases de obstáculos complejos. Contribuye a ocultar las experiencias de las identidades complejas en los procesos de inclusión, especialmente, sus impactos en las trayectorias y en los procesos de biografización subjetiva y material. Las formas ontológicas de la educación inclusiva entrañan diferentes significados atravesados por singulares configuraciones y relaciones espacio-temporales.

La comprensión en uso de las necesidades educativas especiales margina otros tópicos de análisis significativos ligados al entendimiento de la diferencia, la multiplicidad y la singularidad. A través del sintagma no logran ser capturadas todas Rev. Caminhos da Educação: diálogos, culturas e diversidades, Teresina, v. 3, n. 2, p. 113- 127, Mai./Ago. 2021 
Nudos críticos en la comprensión ontológica de la educación inclusiva

las formas nominales de la singularidad y sus criterios de legibilidad en el espacio escolar, inaugurando conceptos imprecisos y deficientes. Sus múltiples usos son el resultado de elaboraciones contingentes al interior de una formación social específica, un constructo histórico y político que prolifera y es regulado por un determinado encuadre cultural.

La categoría de diferencia cuyos usos son empleados desde el mainstream discursivo y teórico de la educación inclusiva en términos universales, posee significados y dispositivos semióticos normativos al utilizarse en diversos contextos académicos y culturales, encubriendo así, un sistema de negación y negociación patológica de la diferencia -alteridad peyorativa, sin re-significación de sus dispositivos semiológicos corporificados-. ¿A qué cosas alude en diversas comunidades? Por norma, tiende a reproducir un efecto que encubre un conjunto de categorías de orden biopolítico. Si somos justos, el sintagma 'necesidades educativas especiales' es un anglicismo normo-céntrico y eurocéntrico que progresivamente se extendió por todo el globo, con el que no siempre logran sentirse identificados un porcentaje significativo de colectividades estudiantiles, estableciendo un sistema de adherencia a una comunidad imaginaria homogénea.

La visión ontológica de lo menor rechaza la forma homogénea de las N.E.E. -término general para referirse a estudiantes afectados por diversas clases de obstáculos complejos-, toma distancia de las diversas clases de compromisos que han sido construidos en torno a una estructura regulada por binarismos dualistas -premisa central en la dialéctica hegeliana- que borra la impronta de la singularidad.

En esta concepción de orden normo-céntrica, la diferencia se establece y construye a través de una relación de oposición más que de encuentro con los múltiples modos de existencia del ser humano. Lo menor en la ontología de lo inclusivo adhiere a un compromiso anti-hegeliano, asume que,

[...] las identidades son aspectos cambiantes, plurales y dinámicos de todas las relaciones sociales. No se trata únicamente de cómo nos observamos a nosotras mismas, sino de que también es un producto social negociado a través del tiempo y el espacio, construido dentro de jerarquías de poder (ANG-LYGATE, 2008, p.301). 
¿Cuáles son las estructuras de poder que atrapan a determinados estudiantes significados como parte del efecto discursivo de lo normo-inclusivo? Los entendimientos instituidos como parte de la educación inclusiva se encuentran montados sobre una gran estructura de opresión, dominación y de individualismosesencialismos, que regulan singulares tácticas de producción de categorías que ficcionalizan las posibilidades objetivas de una gran constelación de ciudadanosestudiantes.

El sintagma necesidades educativas especiales se vincula erróneamente a la fuerza de lo inclusivo a través de un efecto mimético de carácter normativo, atrapando a múltiples sujetos educativos en un peculiar espacio de abyección. El problema es que a pesar que la corriente interactiva de la misma define que es un concepto que abarca a la totalidad de estudiantes, tal efecto se desvanece a través de la retórica visual que impone; demostrando un compromiso persistente con el esencialismo y el individualismo ontológico y metodológico. Inaugura una concepción de inclusión de carácter liberal.

Una de sus obstrucciones ontológicas describe un sistema de enunciación acerca de un sujeto inferiorizado, trama en el que el yo y el nosotros articulan ficciones cambiantes en sus usos ontológicos. Crea un espacio psíquico-pedagógico cargado de imágenes fantasmales. Toda figuración y fuerza ontológica que desee ser significada como parte de lo inclusivo examinará con cautela la relación experiencia colectiva y tramas de subjetividad. En adelante, víctimas de la imaginación esencialista. El análisis de las formas cambiantes y oblicuas de la pluralidad de mecanismos de exclusión, opresión y dominación que afectan sustantivamente a la vida de las personas, muestran cómo ciertas prácticas de inclusión diferencial encubren formas binarias al encontrarse en una gran red de interacciones.

El concepto de vulnerabilidad tiende a emplearse en términos de marginación y subordinación. Los conceptos de inclusión, resistencia, vulnerabilidad, exclusión y otras formas categoriales alojadas en torno a la noción de desmedro social develan una profunda implicancia afectiva. La condición de abyección se encuentra imbricada con los dispositivos de la vulnerabilidad, cuyo enlace reside en que la "conexión solo se vuelve factible cuando vulnerabilidad se entiende, no como una cualidad intrínseca de ningún grupo o "debilidad", sino 
Nudos críticos en la comprensión ontológica de la educación inclusiva

como una tensión entre subyugación y resistencia, incrustada tanto en estructuras sociales como psíquicas” (KYROLÖ, RYBERG y KOIVUNEN, 2019, p.7).

[...] La díada agencia / estructura a través de la cual se supone que se forjan y se negocian las identidades no da cuenta de forma suficiente de las relaciones de poder desiguales que existen no solo a nivel de agencia personal sino también en el ámbito de las estructuras institucionalizadas que perpetúan la supremacía (ANG-LYGATE, 2008, p.301-302).

Los criterios de legibilidad comúnmente empleados para comprender a los sujetos educativos son, en cierta medida, el resultado del imaginario dominantenormativo, fundado en una estructura cognitiva de categorización que deviene en singulares modos de materialidad individual-esencialista. En este punto, proliferan dos interrogantes filosas y sudorosas que tensionan la vigencia y fertilidad del sintagma de necesidades educativas especiales: ¿quién se identifica como estudiante con este término?, ¿qué tramas subjetivas construye el término?, ¿quién decide qué esta categoría debe ser aplicada? y ¿bajo qué coordenadas y oportunidades se cristaliza esta decisión?

\section{Inclusión, sujeto e identidad}

La redefinición ontológica de la educación inclusiva se funda en los principios de la revolución molecular, es decir, en lo menor -las múltiples singularidades-, núcleo relacional complejo que trabaja por fuera y más allá del sujeto unitario establecido por el individualismo-esencialismo. La educación inclusiva es un dispositivo que "engendra una forma pragmática de micropolítica que refleja la naturaleza compleja y nómada de los sistemas sociales contemporáneos y de los sujetos que los habitan" (BRAIDOT'TI, 2013, p.35).

El estudio de las diferencias surge de la tríada analítica entre las relaciones de poder, los sistemas explicativos legados por las verdades científicas y sus prácticas discursivas, operación que subvierte las formas de naturalización y normatividad ligadas a la producción de las identidades. La inclusión rechaza las concepciones de sujeto justificadas por el "esquema dialéctico del pensamiento, donde la diferencia o la alteridad jugaron un papel constitutivo, delimitando el otro sexualizado (mujer), el 
otro racializado (el nativo) y el otro naturalizado (animales, medio ambiente o tierra)" (BRAIDOTTI, 2013, p.35). Agrega la teórica feminista especificando que,

[...] los procesos dialécticos negativos de sexualización, racialización y naturalización de los marginados o excluidos tienen otra implicación importante: resultan en la producción activa de medias verdades o formas de parcialidad conocimiento sobre estos otros. La alteridad dialéctica y peyorativa induce una ignorancia estructural sobre aquellos que, por siendo otros, se postulan como el exterior de las principales categorías divide en la atribución de Humanidad. Paul Gilroy (2010) se refiere a este fenómeno como "agnatología" o forzado e ignorancia estructural. Este es uno de los efectos paradójicos del supuesto alcance universalista del conocimiento humanista (BRAIDOT'TI, 2013, p.36).

La educación inclusiva es un territorio académico, investigativo y profesional que trabaja desde su emergencia articulando políticas de identidad de carácter reduccionistas que contribuyen a perpetuar la vigencia de una gramática ontopedagógica de carácter esencialista-individualista y de una analítica ciega centrada en la herencia de la dialéctica hegeliana que reproduce sistemas categoriales de oposición. Estas son algunas de las manifestaciones del régimen normo-céntrico y especial-céntrico concebido como formas de inclusión. Este halo de regulación ontológica establece criterios de legibilidad que conciben a la diferencia y la otredad desde coordenadas que legitiman los principios de la zona del ser.

La inclusión que más conocemos es el resultado de una elaboración pseudoética coherente con las premisas de regulación de la zona del ser, espacialidad ontológica y pedagógica que crea singulares mecanismos de denuncia y visibilización de los múltiples problemas que afectan a poblaciones atravesadas por el significante de la subalternidad y de la ausencia de reciprocidad, sin alterar las fuentes constitutivas y regulativas de la materialidad de tales problemáticas, entre ellos, lo que hace la exclusión y la opresión a nivel psíquico y material.

La inclusión que prolifera por la zona del ser crea códigos de ordenación y aparatos discursivos-semiológicos que son incapaces de liberar mediante una pragmática epistemológica, los problemas que enfrentan diversas colectividades -alteridad abyecta-. La diferencia y la otredad en la interioridad de las propuestas de inclusión elaboradas por la zona del ser, adhieren a una singularidad estática, 
Nudos críticos en la comprensión ontológica de la educación inclusiva

homogénea y universal de la diferencia, reforzando una política de representación de sujetos propia del humanismo clásico. El interés por la trama de regulaciones ontológicas de la educación inclusiva coloca en tensión las unidades básicas de referencia del ser humano.

La inclusión y la educación inclusiva que más conocemos revela un profundo compromiso con el individualismo y el liberalismo, intersección que da paso a diversas formas de pseudo-inclusión, inclusión opresiva, esencialista y liberal. El desafío es consolidar una pragmática epistemológica de carácter micropolítica y una política ontológica anti-humanista; una trama ontológica configurada por sus propios términos de referencia. Uno de sus propósitos consiste en subvertir las políticas de legibilidad del sujeto y de sus identidades, tal como sostiene Parmar (2008),

[...] «en relación a», «en oposición a», «como el reverso de» o «como un correctivo de», sino referencias en y para nosotras mismas. Dicha narrativa desbarata la jerarquía binaria entre el centro y lo marginal: lo marginal rechaza así su lugar como lo «Otro» (p.246).

La educación inclusiva que practico toma distancia del patrón de sujeción ontológica normativa que entiende a los sujetos como fijos y estables, sino que, asume que las identidades son cambiantes, dinámicas y fluidas, una de las principales características constitutivas de la inclusión como proyecto político. La epistemología de la educación inclusiva desestabiliza el patrón de identidades y las jerarquías fijas de opresión y dominación, entendidas como frenos al auto-desarrollo y a la autoconstitución.

Los sujetos constitutivos de la inclusión mal designados por el patrón occidentalocéntrico que define la zona del ser y sus pseudo-coordenadas de otredad, como minorías -en adelante, mayorías en el mundo- son cotidianamente obligados, incluso, en políticas afirmativas devenidas en prácticas de acomodación, a asumir una posición semiológica de invisibilización dentro de los discursos cotidianos. El problema es el siguiente: la inclusión como la hemos conocido no crea un diagrama de posiciones contingentes para articular nuevas y desconocidas formas de 
identidades. Este es un espacio integrado por múltiples posiciones que se desarman y rearman permanentemente, dando lugar a relaciones y situaciones de carácter transitivas que garanticen una convivencia multi-escalar entre diversas colectividades singulares.

Es necesario rescatar la experiencia subjetiva de los sujetos de la inclusión, que no es otra cosa que, la experiencia de la totalidad de colectivos concebidas como singularidades múltiples. El problema es que nadie habita una identidad fija, ni un modo particular de existir. La inclusión que más conocemos construye una práctica de asimilación y acomodación sobre condiciones diferenciales de exclusión, segregación, dominación etc. A este proceso Ocampo (2017), denomina: 'inclusión a lo mismo'. Proceso caracterizado por la invariabilidad de las estructuras sociales y de escolarización, lo que ha fortalecido

[...] un énfasis en la acumulación de una colección de identidades oprimidas que, por otro lado, han dado lugar a toda una jerarquía de la opresión. Dicha jerarquía no sólo ha sido destructiva, sino también divisora e inmovilizadora. Al no estar dispuestas a trabajar a través de todas nuestras diferencias (PARMAR, 2008, p.251).

Las prácticas de asimilación concebidas como prácticas de inclusión son las que fundan el problema técnico del campo -sistema de abducción a la cultura dominante-, contribuyendo a la regeneración y performatividad del problema ontológico de los grupos sociales. Necesitamos "una política que acepte la «innecesaria o no esencialista correspondencia» de cualquier cosa con cualquier otra; ha de haber una política de la articulación (una política en tanto que proyecto hegemónico)" (PARMAR, 2008, p.252).

La comprensión ontológica de la educación inclusiva sugiere la transformación de las políticas de representación las que se encuentran atravesadas y reguladas por relaciones de poder devenidas y materializadas en determinadas imágenes. El problema es que muchas de estas imágenes trazan imaginarios culturales y posiciones simbólicas en las que determinados colectivos significados como minorías, ingresan en una trama de relaciones de desigualdad respecto del patrón legado por el humanismo clásico. 
Nudos críticos en la comprensión ontológica de la educación inclusiva

La pregunta por las coordenadas de configuración de una ontología de lo menor, reafirma un profundo compromiso con algunos de los principios del antihumanismo, permitiendo la subversión de la ortodoxia semiótico-ontológica que condiciona la producción de criterios de legibilidad cuya "función crítica se extiende al señalamiento de las instituciones fotográficas, que perpetúan y animan la producción y reproducción de imágenes que no contradigan los intereses dominantes de la sociedad" (PARMAR, 2008, p.260). Descentrar la pretensión normo-céntrica del universalismo, es decir,

[...] como rasgo distintivo de la cultura occidental, es decir, su forma específica de particularismo. Usan las herramientas conceptuales proporcionadas por el Humanismo para precipitar una confrontación de la filosofía con sus propias responsabilidades históricas y conceptuales corretaje de poder. Este universalismo humanista, junto con el énfasis del constructivismo social en lo creado por el hombre e históricamente variable naturaleza de las desigualdades sociales, sienta las bases para una sólida ontología política (BRAIDOTTI, 2013, p.20).

En la actualidad, los criterios onto-pedagógicos ligados a la fuerza travestizada del régimen neo-especial crean ficciones y fantasías, develando usos ontológicos restrictivos y equívocos para significar al sujeto de la inclusión, una otredad restrictiva, fundada en el individualismo-metodológico producto de una comprensión homogénea y universal. A través del compromiso con el antihumanismo evitamos la imposición de formas normo-céntricas propiedades del esencialismo y sus modus operandi, cuyas articulaciones han generado singulares modos de reconocimiento que funcionan y operan en la diversidad de estructuras constitutivas del sistema-mundo. Frente a tales demandas, es necesario disponer de mecanismos que comprendan la profundidad y la complejidad de la multiplicidad de singularidades, lo que devela un déficit de especificidad y de vigilancia, articulando "una multiplicidad de problemas sobre la representación” (PARMAR, 2008, p.266) de los sujetos educativos. 


\section{Conclusiones}

Los argumentos presentados permiten sostener que la inclusión a través de su desarrollo intelectual no ha logrado liberar a los sujetos de formas categoriales dominantes de carácter especial-céntricas. En consecuencia, sus propuestas contemporáneas no han sabido distanciarse de las lógicas de operación designadas por la política del humanismo y de la gramática de esencialismos-individualismos que actúan como principios rectores en la constitución de prácticas sociales y educativas a nivel mundial. La educación inclusiva debe "proporcionar oportunidades para la autoidentificación. Y la auto-identificación es el primer paso para el empoderamiento. Si un grupo no se define a sí mismo, entonces será definido por y en beneficio de otros" (HILL COLLINS, 2008, p.35). Sin duda, esto afecta a la teoría y al conocimiento educativo en general.

El espacio ontológico de lo inclusivo se encuentra atravesado por el ser múltiple singular, su imbricación con el humanismo clásico, el sustancialismo y de la matriz de esencialismos-individualismos hacen que las causas y problemas de dichos grupos sean una y universal. Sus formas ontológicas deben dejar de ser concebidas como sustancias de la vida.

La política ontológica de la educación inclusiva destraba las concepciones que cooptan el estatus de ser-humano a múltiples colectivos, lo que para Braidotti (2013), no todas las personas en la historia de la humanidad han disfrutado de dicho estatus, producto del remanente del legado cartesiano y kantiano que conduce a prácticas de binarización y ausencia de reciprocidad. La educación inclusiva construye otra unidad de referencia común para comprender nuestra especie. Insiste Braidotti (2013), comentando que,

[...] el antihumanismo consiste en desvincular al agente humano de esta postura universalista, llamándolo a la tarea, por así decirlo, sobre las acciones concretas que está promulgado. Surgen relaciones de poder diferentes y más nítidas, una vez este sujeto anteriormente dominante se libera (p.23).

Tal trama toma distancia y rechaza la concepción de racionalidad, universalidad y la naturaleza etnocéntrica, lo que "defendió la necesidad de abrirlo a los "otros dentro" (Kristeva, 1991) de tal manera que reubique la diversidad y 
Nudos críticos en la comprensión ontológica de la educación inclusiva

múltiples pertenencias a una posición central como componente estructural de la subjetividad europea” (BRAIDOTTI, 2013, p.33).

Las concepciones predominantes se encuentran atravesadas por relaciones y prácticas de privilegio y poder, afectan a los sujetos a su construcción de subjetividad donde quieran que estos se encuentren. La tarea crítica que enfrenta la educación inclusiva es asumir un eje de movilización más allá de las antiguas -y porque no decirlo, vigentes- categorías dualistas que operan bajo una constelación de alteridades peyorativas, es un llamamiento para construir otro tipo de interacciones y actividad humana.

\section{Referências}

ANG-LYGATE, Magdalene. "Trazar los espacios de deslocalización. De la teorización a la diáspora”, en: Fabardo, M. (Edit.). Feminismos negros. Una antología. (pp.291-314). Madrid: Traficantes de Sueños, 2008.

BRAIDOTTI, Rosi. The posthuman. Cambridge: Polity Press, 2013.

BRAIDOTTI, Rosi. A Theoretical Framework for the Critical Posthumanities. Theory, Culture \& Society, Vol. 0, Núm. 0, 1-31, 2018.

HILL COLLINS, Patricia. "Rasgos distintivos del pensamiento feminista negro", en: Fabardo, M. (Edit.). Feminismos negros. Una antología. (pp.99-133). Madrid: Traficantes de Sueños, 2008.

KYRÖLÖ, Katharina., RYBERG, Ingrid. \& KOIVUNEN, Anu. Vulnerability as political language, 2019. Recuperado el 24 de junio de 2020: https://www.manchesteropenhive.com/view/9781526133113/9781526133113.00005.xml

OCAMPO, Aldo. Epistemología de la educación inclusiva. Granada: UGR, 2017.

PARMAR, Pratibha. "Feminismo negro: la política como articulación”, en: Fabardo, M. (Edit.). Feminismos negros. Una antología. (pp.245-267). Madrid: Traficantes de Sueños, 2008. 
https://doi.org/10.26694/caedu.v3i2.12828

ISSN 2675-1496

(c) 